This item was submitted to Loughborough's Research Repository by the author.

Items in Figshare are protected by copyright, with all rights reserved, unless otherwise indicated.

\title{
Performance related design and construction of road foundations - review of the recent changes to UK practice
}

PLEASE CITE THE PUBLISHED VERSION

PUBLISHER

CRC Press (@ Taylor \& Francis)

VERSION

AM (Accepted Manuscript)

\section{PUBLISHER STATEMENT}

This work is made available according to the conditions of the Creative Commons Attribution-NonCommercialNoDerivatives 4.0 International (CC BY-NC-ND 4.0) licence. Full details of this licence are available at: https://creativecommons.org/licenses/by-nc-nd/4.0/

\section{LICENCE}

CC BY-NC-ND 4.0

\section{REPOSITORY RECORD}

Fleming, Paul R., Matthew W. Frost, P.J. Gilbert, and P. Coney. 2019. "Performance Related Design and Construction of Road Foundations - Review of the Recent Changes to UK Practice". figshare.

https://hdl.handle.net/2134/17259. 


\title{
Performance Related Design and Construction of Road Foundations - Review of the Recent Changes to UK Practice
}

\author{
P R Fleming \& M. W. Frost \\ Department of Civil and building engineering, Loughborough University, England. \\ P. J. Gilbert \& P. Coney \\ Atkins Geotechnics, UK
}

\begin{abstract}
Recently there has been a radical change to incorporate performance related design and compliance testing for UK highway foundations. New guidance has been introduced in the Highway Agency's Interim Advice Note 73/06. The potential rewards of this approach include the wider use of more sustainable marginal materials and savings due to the thinning of the upper structural pavement layers, as well as obtaining useful information relating to expected pavement life. This new framework relies heavily on performancerelated testing during construction to assess if set performance targets have been met. This in turn requires very clear specifications for construction, to ensure the risks of non-compliance are managed and the potential for dispute is limited. Therefore the use of pre-construction site trials are proposed, which in some cases may be costly or impractical (due to accessibility of the location, or relevance of the subgrade conditions). A more holistic approach to pavement design is provided which whilst providing some benefits has resulted in little guidance on the prediction and management of sub-grade conditions which strongly influence the overall pavement performance. Combining the above with an 'observational' method would enhance the performance approach by utilising a greater requirement to understand the site conditions and permit simple and appropriate changes to be made during construction to overcome any variability encountered, and ensure small areas of low performance are adequately managed and remediated. This paper describes the development and key elements of the current performance related guidance, and describes case studies for the observational approach used in road construction schemes. It discusses the merits and limitations of both approaches, and proposes an appropriate step that could be made to better combine and integrate these procedures into a robust practical method for designing and specifying road foundations for the future.
\end{abstract}

\section{INTRODUCTION}

\subsection{Background}

The introduction of the new guidance in the Highways Agency's Interim Advice Note 73/06 (IAN 73 , 2006) comprises a radical change in design and specification for UK highway foundations. The foundations permissible are separated into four classes, as defined by their stiffness. Two design processes, 'performance' and 'restricted' are described in the IAN. The potential rewards of the performance approach include: the efficient and wider use of more sustainable marginal materials; provide some assurance that the material performance assumptions made in the design are likely to be achieved; and recognise the structural contribution of improved foundations (with savings due to the thinning of the upper structural pavement layers, now permitted in HD26/06 (DMRB, 2006).

\subsection{Paper content}

In the following sections the developments and key elements of the performance related guidance are explained, and case studies for the observational approach used in recent construction schemes are outlined. The merits and limitations of these approaches to design are discussed, and proposals for an appropriate step are made to combine and integrate these procedures into an enhanced and robust practical method for design and specification.

This paper is intended as a catalyst for debate on the long-term future of road foundation design and specification in the UK.

\section{PERFORMANCE RELATED SPECIFICATION}

\subsection{Development and Key Elements}

The performance related specification and design guidance embodied in IAN 73 embodies a radical change from what was previously contained in the 
UK guidance (HD25/94, withdrawn February 2006) for road foundations.

In essence, three aspects of design and specification research and development have been implemented in a short space of time during 2006, and the latter two are embodied within IAN 73. These are:

1. new upper road pavement layer design guidance given in HD26/06 (thickness design based on forecast traffic but which permits a thinning of the layers for the higher stiffness class of foundations);

2. new design guidance for the four foundation classes (superseding HD25/94);

3. updated specification clauses for the MCHW (series 800) for material selection criteria, and laboratory and field testing requirements.

The IAN published in 2006 is currently undergoing a review by the HA and is expected to be rereleased in 2008 for further discussion.

The four foundation classes permissible are defined by their long-term minimum stiffness "at top of foundation level":-

- Class 1 - $50 \mathrm{MPa}$

- Class 2-100 MPa

- Class 3-200 MPa

- Class 4-400 MPa .

It is evident that Class 2 represents the equivalent traditional granular sub-base on subgrade (with capping if required), whilst classes 3 and 4 represent superior stiffer foundations requiring the use of stabilised mixtures. Class 1 is only acceptable for minor roads.

A fundamental assumption within the new guidance is that the short-term stiffness (during construction) is an appropriate indicator of long-term performance - utilising some modification factors to adjust the short-term values to allow for confinement (of granular materials) or cracking (of stabilised materials) etc. The foundation 'Performance Design' method allows the designer to predict the likely foundation surface modulus (i.e. assuming all the foundation layers act as an homogeneous elastic half space under a dynamic plate test) that will be achieved by specific combinations of foundation layers over different types of natural ground (subgrade). The key difference here to previous advice for analytical design in LR1132 (Powell et al 1984) is the flexibility to choose an appropriate layer stiffness value for the subgrade (based on expected CBR), capping (granular or stabilised) and sub-base (granular or stabilised) to determine the likely foundation surface modulus. Thus, there are many more theoretical permutations and combinations of design thickness than previously permitted, notwithstanding practical aspects of tolerance and compactibility.

In addition to the introduction of routine insitu stiffness testing during construction, CBR testing of the subgrade is (still) required during construction (using a dynamic cone preferably) to check it is equal to or greater than the design value for each section of the scheme. Adequate material density is required for compacted granular layers, to avoid poor workmanship or problems of temporary high stiffness. A range of material compliance tests is still specified, including size range.

The 'Performance Design' guidance requires a demonstration area to be constructed and carefully evaluated, to confirm the materials and methods will meet the proposed foundation class. Lightweight insitu stiffness measuring devices may be utilised in the main works if they have been properly correlated with the full-scale (trailer mounted) Falling Weight Deflectometer, which is designated as the primary compliance test method. The selection of an appropriate section and subgrade area on which to construct the demonstration area is important, the IAN specifies how to adjust the measured foundation surface modulus to suit the specific demonstration subgrade conditions at the time of the trial. Failure requires re-design, construction and re-testing of the trial.

In addition to the stiffness testing, related to analytical design fundamentals (i.e. limiting stress criterion etc), there is also designated a trafficking trial in the demonstration area, with specific pass/fail criteria for cumulative rut depth. This is to demonstrate the design is also suitable to protect the subgrade from excessive deformation, and the foundation layers from excessive internal shearing, likely to be caused by construction traffic.

There will be significant cost increases to deliver this new approach, including:- the large amount of design and testing of the subgrade (at the state anticipated during construction), proposed foundation materials; site demonstration trial(s), construction compliance testing, and time programmed for approval of layers.

\section{MERITS AND LIMITATIONS OF IAN 73}

There are many potential benefits accrued from the introduction of performance related specifications for road design and construction. IAN 73 embodies the design philosophy set out in HD26/06 aimed at improved 'whole life value' and sustainability. Furthermore, the processes described in IAN 73 suggest the appropriate (re)use of materials within sound scientific designs and measured by new test technology. Better assurance of performance provides better risk control, potential for innovation and long-term developments in materials and technology, and ultimately better user satisfaction. It could be argued that the realisation of these ideals has been a long time coming. However, the issue for debate is has this goal been delivered in the amalgam of documents, and might the changes bring other problems. 
Industry has identified what it considers to be a number of potential limitations of the IAN 73. These include conservative thickness requirements for the 'restricted design' method, and costly extensive testing is required within the 'performance design method. For Class 2 foundations this is potentially inappropriate in some circumstances considering the design thickness of capping and sub-base is similar to that previously required by HD25/94.

In addition, there is limited advice on flexibility for the designer and constructor once on site, it appears assumed that the subgrade behaviour, and all the placed foundation materials and methods will be well defined, understood, and approved at the site demonstration trial stage. However, the proposed site demonstration trials are subject to many influencing variables, including physical access to appropriate subgrade conditions, suitable weather, (or allowance for wetting/drying effects), and the programming of complex trials with extensive monitoring prior to the main contract works.

Problems, disputes and uncertainty during the trials may have a large influence on the ongoing programme and cost. The assessment of suitable performance is largely limited to numerical and statistical analysis of the subgrade, capping and subbase material field data. Potentially little scope has been allowed for detailed geotechnical assessment, nor allowance for uncertainty of the overall ground conditions (such as site specific factors relating to the insitu soils and groundwater) although this is perhaps a natural consequence of a specification based on formulaic end product testing.

However, it is clear that the problem facing the design engineer is the need to propose (suitable) pavement foundations, in circumstances of variable ground and groundwater conditions, allowing for the range of influencing factors that often occur in UK soils, as described further below.

\subsection{Sub-grade factors}

To a practicing geotechnical engineer it appears that the main reason to determine the four foundation classes described in IAN 73 is to enable the statistical approach of design of the upper bound layers that is enabled by the new HD26/06. This is a reasonable and valid aim as it should achieve the objective of delivering a holistic approach to pavement design. However, IAN 73 appears to assume that the sub-grade will be consistent, manageable and relatively problem free. This is often not the case as the sub-grade is influenced by very different factors when compared to the other engineered pavement layers. Therefore, a potential geotechnical criticism of the IAN is that it says too little about prediction and management of sub-grade conditions, reducing the art of pavement foundation design to the science of design and measurement of the placed foundation materials.

There appears to be a change in emphasis on what previously constituted the 'earthworks' (which included capping, and the pavement above formation), to now the pavement construction as a whole. Yet the earthworks are still required to deliver a consistent platform for the pavement construction. The result is the importance of the subgrade appears to have been reduced to be considered in a similar manner to any of the other foundation layers defined by a stiffness value. However unlike the other foundation layers the subgrade is variable and its performance is influenced by many factors which are not considered by IAN 73. The factors that apply are site specific but are likely to include some of the following :

o Soil type, grading, (especially for borderline cohesive / granular soils), variability,

o Permeability and stiffness,

o Horizontal and vertical geological variability

o Soil fabric (e.g. lamination)

o Likely presence of hard / soft spots

o Groundwater conditions and drainage

o Topography - transition zones for cut/fill

o Construction procedures adopted and skill of the site foreman to implement these

o Construction season, timing of drainage installation, exposure time of sub-grade, and quality control.

Yet from the above soil stiffness is just one variable. In addition, the Plasticity Index method of CBR prediction (retained in IAN) does not work well on glacial tills or mixed soils.

It would appear that much of the advice in the HD25/94 regarding subgrade issues has been omitted, including aiming for consistent formation stiffness over lengths of $500 \mathrm{~m}$. In addition, little reference is made to the supporting information in HA44/91. In its present form IAN 73 has only 3 of its 62 pages dedicated to advice regarding sub-grade.

The 'Performance Designs' depend largely on demonstration areas to prove the performance of the proposed pavement, yet the subgrade conditions highlighted above will greatly influence the results. This raises some important questions regarding the adequacy of the trials, which include how many test areas should be constructed, and should there be one trial for each combination of ground and/or groundwater conditions?

Experience from a number of projects also shows that in practice the form of contract used can have the greatest influence on the approach taken to capping design. The move to design and build construction and partnering has resulted in very different pressures on the designer to those seen under more traditional re-measure forms of contract (Jarvis and Gilbert 2003). It is considered the geotechnical en- 
gineer must be given enough freedom to assess these various subgrade related factors, to help decide what is the appropriate design approach to deliver the foundation platform required, to then enable the successful optimum construction of the proposed bound layers. This appears to be a weakness of the current interim advice note, IAN 73.

\subsection{Design Benefits}

Within the IAN "Restricted Designs" are included which can be used when the detailed compliance testing for the "Performance Designs" is not appropriate. These designs have been deliberately set to be conservative which is understandable otherwise the performance specification might never be implemented. However, brief observation of the restricted design options suggests that they are possibly more conservative than the designs historically implemented in the UK, e.g. for a granular foundation (combined sub-base and capping):-

1. 300mm required on good granular subgrade (compared to traditional $150 \mathrm{~mm}$ ),

2. $650 \mathrm{~mm}$ required on a good clay sub-grade (when around $400 \mathrm{~mm}$ may traditionally be expected).

The document does not account for this apparent caution. More significantly research undertaken on behalf of the Highways Agency to review the performance of existing roads, designed using the traditionally approaches set out in LR1132 \& HD25/94, indicates that when the foundation design reflects the sub-grade conditions the performance is as expected and adequate (Gilbert et al 2004, and Gilbert et al, 2007).

The design charts given for the Performance Designs do not result in any significant reduction in foundation thickness compared to designs based on HD 25. Furthermore, the designer is encouraged away from the use of capping towards a single foundation layer, as it is only then that relatively thin foundations can be achieved. Yet in practice for many sites the use of capping is advisable to manage the sub-grade conditions. Therefore theoretical benefits of achieving a single foundation layer can only be delivered by construction during "good" construction condition. Designers may have a difficulty justifying the cost of extra testing if they can not offer a reduction in foundation materials and can only rely on savings being achieved in the bound layers design to HD26/06

\subsection{Soil Mechanics and Psychology}

In recent years there have been major changes to how the industry is regulated, with the gradual move from the traditional contract arrangement of a Resident Engineer supervising a Contractor, to various forms of Design and Build contract where a Contractor is required to self certify their work. Anecdo- tally some engineers complain that this has resulted in a lower quality product (although this may be based on a subjective assessment of the past), but few consider why this change has come about. A potentially significant reason for the change is in response to the changing expectations of society, including the personal expectations of engineers, and the lack of experienced professionals within the industry. It is important to recognise these issues, and create engineering methods that can be implemented within the reality of the industry. For pavement engineering this tends to mean that many of those constructing the pavement foundation have limited experience in this field. A good aspect of the IAN is that it provides a useful description of many of the important factors that will influence performance. However, the language used in the document could be considered sufficiently complicated that it is likely to only be read by specialists in the field. This possible perception of lack of accessibility could prove a problem to the industry as it may lead to the construction team not understanding the intentions of the capping design and thus taking no ownership for its successful implementation.

Furthermore, it is apparent that a number of those experienced in pavement foundation design are finding the new 'performance design' approach complicated. This may result in a new form of specialist coming into existence who may give too much emphasis to the theory of the IAN, and due to lack of experience or support from other fields may neglect the many other influential aspects of a road construction project that lead to its success. This issue could be resolved by appropriate training, including widely disseminated feedback from projects utilising the performance based design approach.

It would therefore seem clear that as highway engineers we should not consider just the theoretical soil mechanics of the proposed new design method but also the psychological response of the industry that will receive it. If the method is too complicated for the majority of those in the industry then it may fail to deliver fit for purpose solutions as intended.

\subsection{Stiffness / test methods}

It is fair to say geotechnical and pavement engineers recognise that if a simple method is developed to model stiffness of the sub-grade and the pavement foundation layers then this would lead to a significant improvement in the theory behind foundation design. However, identifying a low cost test method that can be implemented both in the laboratory (at investigation stage) and in-situ (during construction) has proven difficult. The IAN has been released on the assumption that the Falling Weight Deflectometer (FWD) and/or Light Weight Deflectometer (LWD) can fulfil this role, but has retained subgrade 
CBR as a design/assessment measure through necessity.

The use of the (large and relatively expensive) FWD to control earthworks construction is not currently considered a realistic proposition for routine work; therefore the (portable) LWD approach has been developed. However, a review of a wide body of data from various LWD development trials on capping materials has shown that the stiffness values determined can vary significantly and this is complicated further by the large number of factors that can influence this variability, from the material properties and material states and this is a concern (Lambert, 2007).

Whilst the IAN focuses on stiffness, the designer will continue to have to divide the site into lengths of pavement of one expected sub-grade foundation requirement based on an assessment of the wide range of site issues described above. These lengths are ideally $500 \mathrm{~m}$ or more in length, along which the in-situ stiffness will vary (Fleming et al, 2000), the designer will therefore consider the stiffness data set as just one of the many variables.

During construction simple methods are required that enable the works to progress without interruptions (delays can lead to deterioration of the exposed sub-grade). This can be achieved by methods such as visual inspection backed up by a simple in-situ test (e.g. LWD or the dynamic cone penetrometer) to identify areas of softer than expected subgrade. Those on site could continue to use the empirical CBR as a subgrade condition descriptor which is widely understood and may still be adequate as a quick empirical control measure for the site works in partnership with other tests. This can be managed as part of the design process via an 'Observational Approach' that many in the industry are currently implementing (described further in Section 4).

One major benefit of the LWD testing is that it can be used for complementary laboratory trials of relatively unusual capping materials (e.g. recycled aggregates) prior to going to site. However, the cost of undertaking such laboratory trials is high due to the requirement to prepare large samples to obtain meaningful results (Lambert, 2007); this could restrict the materials considered and trialled to only those projects where there is scope for adequate savings to be made by investing in extra laboratory testing. However these tests are considered to have a role in material approval tests for suppliers. This leads to a major benefit of the IAN which is to use it for undertaking source approval paid for by the proposed supplier and then made available to all contractors who wish to consider using that material. This approach is widespread for other industry materials, and thus reduces the contractors costs to those for the in-situ testing during construction.

However the ongoing absence of advice on the methods to assess durability of unusual and recycled aggregates may continue to restrict the range of materials considered.

\section{OBSERVATIONAL APPROACH}

\subsection{Key Elements}

The flexibility required in design where variable site conditions are encountered during construction (or limited pre-construction site data is available) is embodied in the 'observational approach' (Nicholson et al, 1999). A similar methodology has been developed for a number of Design and Build schemes (Gilbert, 2004) and has proved appropriate for large highway foundation areas and allows swift construction.

This was achieved by including in contract documents full details of expected ground and groundwater conditions, predicted pavement foundation requirements, a defined regime of site inspection coupled with rapid insitu testing methods to obtain the data to identify locations where the conditions differ from those expected, and clear procedures developed to enable changes to be made on site based on the actual conditions encountered. This allows the designer to make realistic predictions of a range of pavement foundation requirements.

However for this approach to work trust and cooperation is required between all parties (Client, Contractor and designer), to allow the optimum foundation for the scheme to be built. Key construction issues for the project are identified and the design/specification prepared accordingly, to include/allow, for example, for variation in the amount of construction traffic using the capping (less than the normally assumed 1000 standard axles), exact timing of subgrade drainage installation (and hence the likely long-term equilibrium CBR predictions), the influence of compaction of the sub-formation to overcome disturbance during excavations, accommodation of stripping of subgrade after adverse weather (or if softening has occurred - incorporating associated thickening of capping). This needs effective site inspection regimes and quick short-term testing regimes to be utilised, with transition zones being given special attention particularly cut/fill intersections. The approach of the designer is to make maximum use of the materials available on site to form a suitable foundation for the pavement, this can extend past the limited classification of capping materials given in HD25/94 and is one of the aims of the IAN.

\subsection{Project example.}

As previously described a simple Observational Approach to pavement foundation design has been used on various Design and Build road schemes over the past 12 years (Gilbert, 2004). The approach has been gradually developed, and was used as part of 
the strategy for the M6 Toll Road. It enabled a broadening of the acceptable range of capping materials used on the Glasgow Southern Orbital / M77 . Performance of these roads to date has been positive (Gilbert at al, 2007). Recently it has been developed to suit requirements in the Republic of Ireland by providing a flexible tool to enable a Contractor to keep construction options open and is further discussed below.

The N6 PPP scheme at Galway is a two lane dual carriageway currently under construction. The geology includes soft alluvium, Glacial Till and solid geology of limestone. The Glacial Till is of variable grading from cohesive material with high sand and gravel content, to a granular material with a significant fines content, changing dramatically over very short distances. One common factor is that the soil is highly moisture susceptible. Undulating topography along the route gives regular transitions from cut to fill and long sections of at-grade or on low embankment. The simplest way to manage these variable conditions has been to define a number of "Capping and Sub-base scenarios" based on:-

1. Alignment / topography condition (Cutting, atgrade / low embankment, embankment $>1 \mathrm{~m}$, transition zone).

2. Sub-grade condition (principally soil type as groundwater is generally high).

3. Design CBR.

4. Foundation design options for each soil type: sub-base only or sub-base \& capping

5. Additional measures for soft ground.

Each earthwork drawing shows the Capping and Sub-base scenarios that are applicable to each length of main highway (leaving the foundation choice open to the Contractor), and identifies areas of continued uncertainty where special attention is required.

The scheme's Specification Appendix 6/7 then defines a set of requirements for the sub-grade to be implemented as part of the Contractors inspection and test plan. These are underpinned by:-

1. A visual inspection of the subgrade, including a review of the fines content and whether the design CBR is appropriate.

2. In-situ CBR testing by hand held dynamic probe (set of 3 tests at $20 \mathrm{~m}$ centres).

3. A defined procedure for re-assessment of design CBR values.

The approach described enables the observed ground conditions to be accommodated within the design, so that the construction is appropriate for the ground conditions. Any reduction in pavement foundation thickness is only permitted if there is an improvement in the ground conditions encountered; changes, based on short term in-situ CBR test results alone are not permitted as the design is based on predicted equilibrium water content CBR values.
Importantly the in-situ stiffness is used as a simple check of the expected ground conditions by comparison to predicted CBR; the LWD could be used for this purpose, but initially would still only be a tool to help identify variability (not a measure of absolute stiffness).

\section{DISCUSSION - INTEGRATION OF THE TWO METHODS}

The newly published advice regarding 'performance designs' for road foundations has incorporated many important facets including 'fit for purpose' materials and their fundamental properties in the design of adequate foundation thickness. The recognition of superior performance, and site compliance testing is well received and perhaps long overdue. However, it is also clear that the new guidance represents a sea change in the use of 'stiffness' both as a design and compliance parameter. It is also apparent that to avoid potential problems (as far as is practicable) the new guidance is very formulaic in its design steps, although the use of appropriate site trials should engender greater confidence (notwithstanding the comments in section 3.1). It undoubtedly requires the designer of a scheme to gather a relatively large volume of data prior to any detailed design and to make many assumptions, arguably the most significant is the uniformity and expected subgrade state during construction. The guidance appears to lack some flexibility in decision making during construction that could help deal with variable ground conditions or disputes if the measured values fall slightly below a foundation class requirements (for reasons other than poor materials or workmanship).

The observational approach, however, embraces much of the philosophy of the performance approach but with the added enhancement of anticipation of site variability and a pragmatic action plan to deal with the arising problems this may bring. The observational approach requires the designer to think through soil behaviour, review ground conditions, and develop a strategy to suit the project, rather than follow a formulaic design code.

It is clear that effective integration of the observational approach into a performance based specification is likely to be appropriate only where there is an appropriate form of contract to help share risks between the designer and constructor. However, where this is the case the maximum benefits can be accrued by both parties, and hence any site related problems overcome.

For the performance design method to effectively allow for variable subgrades, it implies that a demonstration trial is required for each possible eventuality. A potentially more practical scenario is to set out clearer guidelines within the advice regarding a framework for the interpretation of the subgrade 
(drawing more from the valuable insights given in previous HA design guidance), utilising the latest test techniques being developed within the observational approach and with the use of GIS databases for asset management. This would be a significant undertaking with regards to capturing the essential aspects of how experienced geotechnical engineers carry out their work with regard to highway design, but from an industry view this would add significantly to the advice.

Current research into earthworks performance specifications, a new draft British Standard (BS6031), and the use of intelligent compaction monitoring equipment; could usefully feed into any future review process. In addition, the move towards effective asset management has led to the demand for effective capture of site data (during construction) for future maintenance management and intervention strategies. This will become increasingly important for longer-term climate change impact research and mitigation strategies. Such data would make widening and reconstruction projects more effective, and could include the site measured performance related data on the foundation as well as the soils. Recent work has shown the benefit of such a geotechnical database for asset management of pavement foundations (Gilbert et al, 2007).

It is also interesting to note that research in Germany has highlighted a link between subgrade stiffness variability and the development of spatial variability in ride quality (Grabe et al, 2005). This points clearly to a possible long-term ride quality benefits of controlling foundation stiffness consistency and is similar to the effects observed in railway trackbed performance. This is where part of the original Department of Transport research regarding compliance testing of road foundations began in the 1980s (Cobbe 1986), the observational approach described herein also may help to address this.

The requirements of the IAN are perceived by some in the industry to be relatively complex and expensive. It will be interesting to see how widely and effectively it is implemented.

\section{CONCLUSIONS \& RECOMMENDATIONS}

This paper considers the change in approach and philosophy to pavement foundation design that is proposed for the UK via IAN 73. The new code has two principal benefits:-

1. It provides a stiffness based philosophy that will enable the pavement foundation to be designed as part of an overall pavement solution. This should enable greater optimisation of design to be delivered for the more expensive bound layers (designed to HD26/06) using the true foundation support as an upper layer design input. This benefit is most achievable when stabilised materials are used for the foundation layers.

2. It also provides a framework that will enable utilisation of alternative foundation materials such as re-cycled and more marginal aggregates.

However, the drive to improve the theoretical aspects of pavement foundation design could potentially be to the detriment of the practical consideration of the geotechnical issues associated with the capping. It must be remembered that on many sites the primary objective of the capping is to provide a stable foundation upon which the other layers can be constructed, as the capping is used to manage subgrade problems and variability.

The aim of using more re-cycled aggregates may potentially be more successful if the approach allowed the test approach listed as "performance designs” to form a material type/source approval.

From an industry perspective, the restricted designs allowed in IAN 73 are considered conservative, and seem to make little allowance for the experience gained with such standard designs or materials over many years. However the additional thickness from the new designs may be required to ensure stiffness targets are achieved, allowing for the observed site stiffness data variability.

Consequently on many sites there is the potential risk that the benefits of the IAN will not be achieved as thick standard foundations may be called for , and the extra costs involved will deliver no significant benefit over traditional designs.

This paper considers the possibility of modifying the approach within the IAN to incorporate subgrade management to increase flexibility on site. This can be achieved on appropriate sites and projects with a move from a "performance" based approach to encompass an "observational” approach.

Due to the challenges of accurate long-term performance prediction and design, true performance specifications will only be achieved when these aspects can be addressed, which includes the requirement of a suitable form of contract and appropriate test methods.

It is a concern from some in industry that if the IAN were fully implemented designers would struggle with its requirements and contractors would not have the experience or background skills to implement it as intended.

To take the IAN forward it is proposed that it's status should be modified to possibly work in partnership with aspects of the old HD25/94, and that an industry review of IAN should be undertaken to look at it's impact, understanding and implementation. The feedback should then be used to update the advice and guidance, and training, in perhaps two years time 


\section{REFERENCES}

Brown, S.F. Soil Mechanics in Pavement Engineering. 36th Rankine Lecture of the British Geotechnical Society. Geotechnique, Vol. 46, No. 3, pp. 383-426. 1996.

Cobbe M. I., 1986, Development of Acceptance Criteria for Subgrade Improvement Layers, Report to Engineering Intelligence Division, Department of Transport, London.

Fleming P R, Rogers CDF, Thom N, Frost, A performance Specification for Pavement Foundations, Transportation Geotechnics 2003, Thomas Telford, pp 161-176, ISBN 0 727732498.

Fleming, P.R., Frost, M.W. and Rogers, C.D., " A comparison of devices for measuring stiffness in situ", Proceedings of Fifth International Conference on Unbound Aggregates in Roads, Nottingham, July 2000, pp 193-200

Gilbert, P. J. 2004. Practical Developments for Pavement Foundation Specification. In proceedings of the international seminar on Geotechnics in Pavement and Railway Design and Construction, Eds. Gomes Correia \& Loizos, Millpress, RotterDam.

Gilbert, P. J., Smith, V., \& Gwede, D. 2007. Geotechnical Asset Management of Pavement Foundations. 2007 PIARC.

Grabe J., Mahutka K., 2005, Long-term evenness of pavements with respect to soil deformations, BCRA5, CD-ROM, Norway

Jarvis, S., Gilbert, P. J., Private Finance Initiative Infrastructure Projects - Implications on Geotechnical Design, Transportation Geotechnics 2003, Thomas Telford, pp 117129, ISBN 0727732498.

Lambert, JP 2007, Novel Assessment Test for Granular road Foundation Materials, Engineering Doctorate thesis, CICE Loughborough University.

Nicholson, D., Tse C-M. \& Penny, C. 1999. The Observational method in Ground Engineering. CIRIA.

Powell, W.D., Potter, J.F., Mayhew, H.C., and Nunn, M.E. (1984): The Structural Design of Bituminous Roads (LR1132). Transport Research Laboratory, Crowthorne Berks. UK.

The Highways Agency. Design Manual for Roads and Bridges: Vol 4 Geotechnics and Drainage: Section 1 Earthworks, Part 1, HA44/91. The Stationery Office, London, 2006,

The Highways Agency. Design Manual for Roads and Bridges: Vol 7 Pavement Design and Maintenance, Part 3, HD 26/06. The Stationery Office, London, 2006.

The Highways Agency. Interim advice note 73/06. Design Guidance for Road Pavement Foundations (Draft HD25). The Stationery Office, London, 2006. 